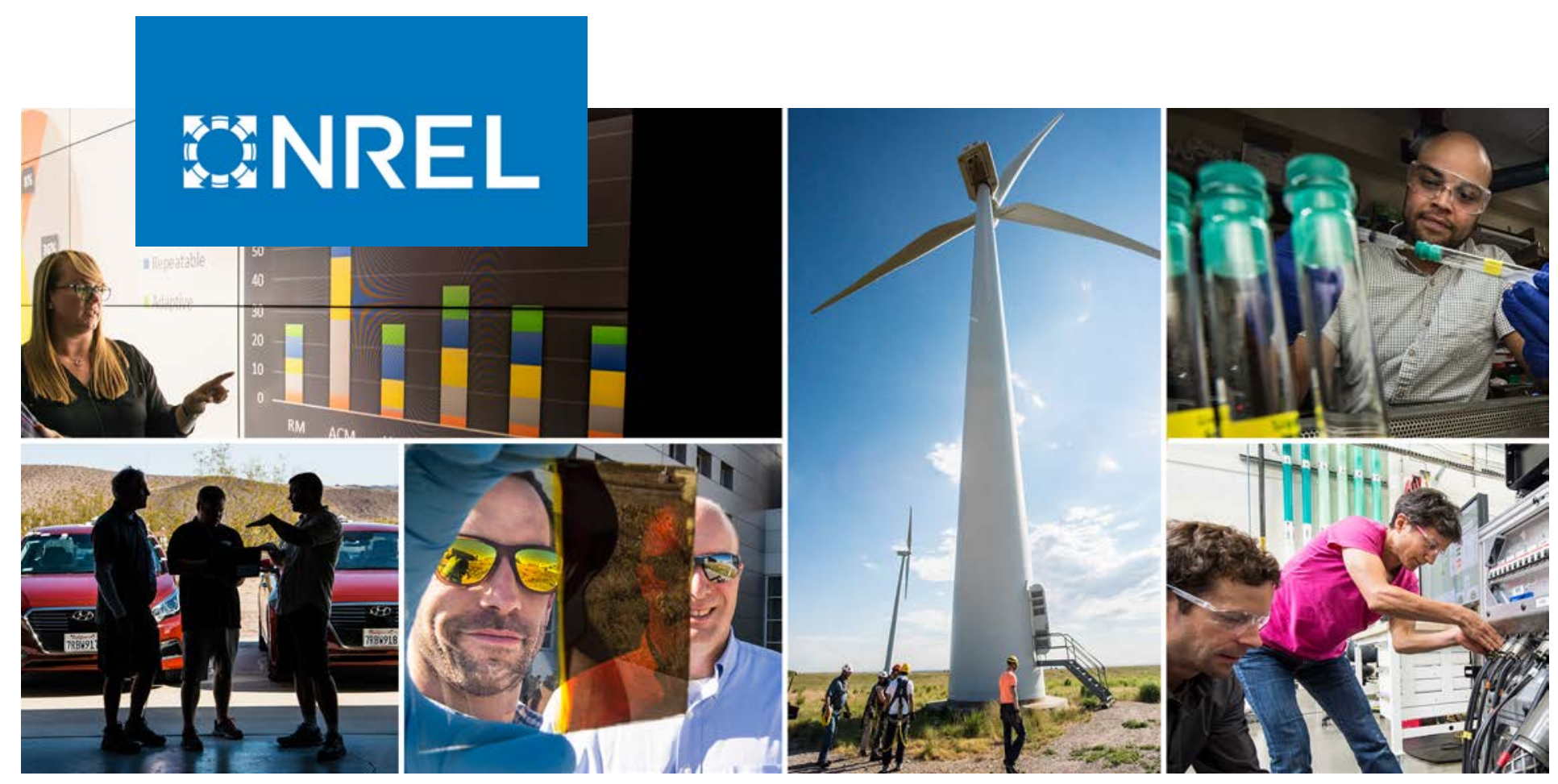

\title{
DNV GL Joint Industry Project on Coupled Analysis of Floating Wind Turbines
}

\author{
Cooperative Research and \\ Development Final Report
}

CRADA Number: CRD-17-672

NREL Technical Contact: Jason Jonkman

NREL is a national laboratory of the U.S. Department of Energy

Office of Energy Efficiency \& Renewable Energy

Operated by the Alliance for Sustainable Energy, LLC

This report is available at no cost from the National Renewable Energy Laboratory (NREL) at www.nrel.gov/publications.
Technical Report

NREL/TP-5000-73165

January 2019 


\section{GNREL}

\section{DNV GL Joint Industry Project on Coupled Analysis of Floating Wind Turbines}

\section{Cooperative Research and Development Final Report}

CRADA Number: CRD-17-672

NREL Technical Contact: Jason Jonkman

\section{Suggested Citation}

Jonkman, Jason 2019. DNV GL Joint Industry Project on Coupled Analysis of Floating Wind Turbines: Cooperative Research and Development Final Report, CRADA Number $C R D-17-672$. Golden, CO: National Renewable Energy Laboratory. NREL/ TP-5000-73165. https://uww.nrel.gov/docs/fy19ost/73165.pdf.

NREL is a national laboratory of the U.S. Department of Energy Office of Energy Efficiency \& Renewable Energy Operated by the Alliance for Sustainable Energy, LLC

This report is available at no cost from the National Renewable Energy Laboratory (NREL) at www.nrel.gov/publications.

Contract No. DE-AC36-08GO28308
Technical Report NREL/TP-5000-73165 January 2019

National Renewable Energy Laboratory 15013 Denver West Parkway Golden, CO 80401 303-275-3000 • www.nrel.gov 


\section{NOTICE}

This work was authored by the National Renewable Energy Laboratory, operated by Alliance for Sustainable Energy, LLC, for the U.S. Department of Energy (DOE) under Contract No. DE-AC36-08GO28308. Funding provided by U.S. Department of Energy Office of Energy Efficiency and Renewable Energy, Wind and Water Technologies Office. The views expressed herein do not necessarily represent the views of the DOE or the U.S. Government.

This report is available at no cost from the National Renewable Energy Laboratory (NREL) at www.nrel.gov/publications.

U.S. Department of Energy (DOE) reports produced after 1991 and a growing number of pre-1991 documents are available free via www.OSTI.gov.

Cover Photos by Dennis Schroeder: (clockwise, left to right) NREL 51934, NREL 45897, NREL 42160, NREL 45891, NREL 48097, NREL 46526.

NREL prints on paper that contains recycled content. 


\section{Cooperative Research and Development Final Report}

In accordance with requirements set forth in the terms of the CRADA agreement, this document is the final CRADA report, including a list of subject inventions, to be forwarded to the DOE Office of Science and Technical Information as part of the commitment to the public to demonstrate results of federally funded research.

Parties to the Agreement: Det Norske Veritas, Danmark A/S (DNV GL)

CRADA number: CRD-17-672

CRADA Title: DNV GL Joint Industry Project on Coupled Analysis of Floating Wind Turbines Joint Work Statement Funding Table showing DOE commitment:

\begin{tabular}{|c|c|}
\hline Estimated Costs & $\begin{array}{r}\text { NREL Shared Resources } \\
\text { a/k/a Government In-Kind }\end{array}$ \\
\hline Year 2 & $\$ 17,500.00$ \\
\hline Year 3 & $\$ 10,500.00$ \\
\hline TOTALS & $\$ 17,400.00$ \\
\hline & $\$ 45,400.00$ \\
\hline
\end{tabular}

\section{Abstract of CRADA Work:}

This shared resource CRADA defines research collaborations between the National Renewable Energy Laboratory (NREL) and Det Norske Veritas (Norway) and Germanischer Lloyd (Germany), known as DNV GL, an international certification body. Under the terms and conditions described in this CRADA agreement, NREL will participate in an offshore wind turbine Joint Industry Project (JIP) led by DNV GL, and including twelve other Joint Industry Project participants, to examine the coupled analysis methodologies needed for the design and verification of floating wind turbines.

The international design standards are implemented by certification companies, such as DNV GL, the organizing agent of the JIP. Through this collaboration, the JIP participants have the ability to improve offshore wind turbine design, internationally, as well as in the United States, and can make this improvement by leveraging the significant aggregation of industry funds that has been organized by DNV GL.

\section{Summary of Research Results:}


The aim of DNV-GL-led JIP was to develop a recommended practice (RP) for floating offshore wind turbine (FOWT) modeling, testing, validation, and loads analysis to aid the industry to meet FOWT design requirements (e.g. IEC 61400-3-2 and DNV-GL design guidelines).

The RP developed within the project covers general design considerations, environmental conditions, numerical modeling, scale-model testing and validation, FOWT controllers, and load case set-up and data analysis. The final document is publically available by request at this link, https://www.dnvgl.com/oilgas/download/dnvgl-rp-c205-environmental-conditions-andenvironmental-loads.html. The RP has a large number of gaps-reflecting current experience in FOWT modeling and analysis - that need to be addressed through further R\&D to better improve the FOWT design process in the future.

NREL's specific contributions to the JIP were as follows:

- Attended a series of net-meetings and five physical meetings (Norway, Greece, Norway, UK, France) to review the project progress and guide the next steps.

- Shared related NREL experience and data as requested with regards to FOWT numerical modeling, scaled-model testing and validation, and loads-analysis research.

- Provided input and propose text for the RP on the topic of floating offshore wind turbine modeling and validation.

- Reviewed and provided feedback on the RP.

Key details of the RP developed within the JIP as taken from the RP are summarized below:

- The RP gives guidance for modeling, loads analysis, and model testing of FOWT. The $\mathrm{RP}$ is based on state-of-the-art within modeling and loads analysis of FOWT. The RP shall be read in conjunction with other standards such as DNVGL-ST-0437 for wind turbine loads and DNVGL-ST-0119 for design of FOWT support structures. The RP specifies general principles and methods for the analysis of FOWTs, to be used in combination to the referenced standards. The objectives of this recommended practice are to:

- Provide an internationally acceptable set of recommendations that fulfill the requirements of the referenced standards for the analysis and the design of FOWTs

- Serve as a reference document between project stakeholders, to agree and align the methods for the design and the analysis of FOWTs

- Serve as a guideline for designers, suppliers, purchasers, and regulators

- Specify procedures and methods for the analysis of FOWTs subjected to DNVGL certification

- Serve as a guidance for planning and execution of ocean basin tests, having the purpose of validating numerical models.

- The development of FOWT can be divided into different levels, see DNVGL-SE-0442:

- Concept level-Feasibility evaluation can be carried out for a generic site or according to specific site conditions defined by the developer.

- Prototype level - A prototype can be built to develop a type certified design. Different tests are normally carried out to validate the design. 
O Site type level - The focus is on the design validation of the floater, the station keeping system, individual floating components, or the full FOWT including an integrated rotor-nacelle assembly (RNA).

- Project level- This is relevant for a farm consisting of a single or several floating wind turbines.

- In general, a site-specific load analysis based on the design basis shall be performed. The load analysis shall include aero-elastic and hydrodynamic effects. This analysis may be performed for one or a few locations only.

- Wind loading is important for prediction of global motion response of floaters. Accurate modeling of the wind effects is therefore essential. For some floating systems and in some load cases, the wind loads can be the dominating excitation.

- Sea states can be classified into:

$\circ$ Wind seas: these are generated by the local wind conditions, and are typically irregular and short-crested.

- Swell seas: these have no relation to the local wind conditions, and are typically long (in terms of wavelength) and more regular and long-crested than wind sea waves.

- Current is of interest for FOWTs as it produces slowly varying loadings that need to be balanced by the station keeping system. A steady current gives rise to steady forces in the horizontal plane. Dynamic loads due to vortex shedding may occur and may interact with the floater giving Vortex Induced Motion (VIM). Slender structures, e.g. mooring lines, may be subjected to Vortex Induced Vibration (VIV) which can lead to fatigue issues and should be considered.

- For strong currents and relatively steep waves, the wave-current interactions should be taken into account when considering air gap and wave impact (slamming) problems, see DNVGL-RP-793 C205. If, for example, the current direction is opposite of the wave direction, this may tend to steepen the waves.

- Tides are seen at a local level as currents and changes in sea level caused by predictable astronomical effects and local weather conditions such as storm surges. The sea level is of concern in this context and can simply be modelled as a change in water level that can be assumed constant throughout a simulation but may vary between simulations.

- In regions, which are considered seismically active, consideration of earthquake events should be made with a guide to determine levels of seismicity available in ISO 19901-2. Seismic events will affect the floating system differently depending on the arrangement of the station keeping which can be divided into two main categories, taut and catenary. For catenary lines, it is expected that these events will cause dynamic mooring line tension loading that may be important for the station keeping system however have minimal impact on the floater and turbine. For taut systems, earthquake motion may also be directly transferred to the floating structure. Furthermore, geotechnical conditions for the anchors should be checked to determine dynamic soil properties and liquefaction potential (ISO 19901-835 4).

- Tsunamis are very long period waves generated by vertical movement of the seabed as a result of an earthquake. Tsunamis need to be considered only for sites prone to tsunamis. Their influence can be modelled as a variance of water surface elevation and a horizontal current following advice found in Annex L of IEC 61400-3-2. 
- In areas where sea ice can occur, there are several sea ice scenarios that potentially can give significant loads on the substructure.

- It is already established that the coupling between the force on the wind turbine and the motion of the floater is crucial to account for, and this applies for all types of concepts. For a FOWT, there is a strong coupling between the floater motions and the turbine forces. This coupling can briefly be outlined as follows:

$\circ$ The motion of the floater will influence the aerodynamic inflow conditions to the turbine and introduce inertial loads on the turbine.

○ The forces acting on the turbine will influence the motion of the floater mainly through hydrodynamic excitation and damping forces. The natural periods of the floater motion may be altered by the wind turbine.

- The aerodynamics of the wind turbine can contribute to the floater stability with a positive or negative damping, depending on the external conditions and the control system.

- For some types of installations there may also exist an important coupling between the station-keeping system and the motions of the floater. This coupling can briefly be outlined as follows:

$\circ$ The wind- and wave-frequency motion of the floater will influence the forces in the mooring system.

- The motion of the station-keeping system will exert forces on the floater, generally both in terms of restoring forces, damping forces, and possible excitation forces.

- It is acknowledged that coupled simulation codes applicable for FOWTs require considerable computational effort. Typical dimensions of a full load case set up vary from $10^{2}$ to $10^{4}$ different load cases resulting in a data volume of several giga bytes up to terra bytes in terms of stored time series. Possible reduction of computational effort without giving up required accuracy of the final results can be done by careful consideration of the variations and combinations of environmental input parameters, suitable adjustment of calculation parameters of the specific simulation code applied, and finally in the consideration of the peculiarities of the floating support structure and RNA design. A common tolerance applied for the accuracy of a reduced load simulation compared to a complete load set up is $+/-5 \%$, corresponding to a $95^{\text {th }}$ percentile of a quasi infinitive number of load cases. Therefore, to reduce the number of simulations required to determine the design driving loads, the following approaches are typically applied:

$\circ$ Clustering of an offshore wind farm into reduced number of representative design positions

$\circ$ During conceptual and front engineering design phase, focusing on reduced set of critical load cases

- For final design loads and for certification, all design load cases of the applied standard should be considered, with an appropriate selection of simulation lengths (including length of initial transient phase), number of seeds, directionality and misalignments, based on the conceptual and front engineering design analysis and additional sensitivity analyses.

- The controller for the floating system (wind turbine and platform) is used to operate the system in such a way that it achieves its objectives of safe operation and energy capture. The controller typically has the ability to manipulate the blade pitch angle, the generator 
torque, shaft brakes, nacelle orientation and possibly ballast levels to achieve these objectives. The controller manipulates these actuators as a function of measured turbine states, which in-turn has an impact in those same turbine states, resulting in a tight coupling between the dynamics of the system and the dynamics of the controller. The addition of a floating platform introduces several challenges that require careful consideration when designing and implementing controllers. In general, it should not be assumed that an existing controller for a bottom-fixed turbine will meet the required objectives when applied to a floating system.

- The recommendations for model testing and validation are to be read in conjunction with the general recommendations for hydrodynamic model testing provided in Chapter 10 of DNVGL-RP-C205. While DNVGL-RP-C205 focus on applications in the Oil \& Gas and Maritime industries, the present RP is focused specifically on model testing of FOWT substructures.

Subject Inventions Listing: None

\section{Report Date:}

August 30, 2018

\section{ROI \#:}

None

Responsible Technical Contact at Alliance/NREL:

Jason Jonkman

Name and Email Address of POC at Company:

Ngoc-Do Nguyen; ngoc-do.nguyen@dnvgl.com

DOE Program Office: Wind and Water Power Technologies

This document contains NO confidential, protectable, or proprietary information. 